\title{
BMJ Open Practical and validated tool to assess falls risk in the primary care setting: a systematic review
}

\author{
Wytske MA Meekes (D) , ${ }^{1}$ Joke C Korevaar, ${ }^{2}$ Chantal J Leemrijse, ${ }^{2}$ \\ Ien $A M$ van de Goor ${ }^{1}$
}

To cite: Meekes WMA, Korevaar JC, Leemrijse CJ, et al. Practical and validated tool to assess falls risk in the primary care setting: a systematic review. BMJ Open 2021;11:e045431. doi:10.1136/ bmjopen-2020-045431

- Prepublication history and additional supplemental material for this paper are available online. To view these files, please visit the journal online (http://dx.doi.org/10.1136/ bmjopen-2020-045431).

Received 05 October 2020 Accepted 18 August 2021

Check for updates

(c) Author(s) (or their employer(s)) 2021. Re-use permitted under CC BY-NC. No commercial re-use. See rights and permissions. Published by BMJ.

${ }^{1}$ Tranzo, Tilburg School of Social and Behavioral Sciences, Tilburg University, Tilburg, The Netherlands

${ }^{2}$ NIVEL, Utrecht, The Netherlands

Correspondence to Wytske MA Meekes;

w.m.a.meekes@

tilburguniversity.edu

\section{ABSTRACT}

Objective Although several falls risk assessment tools are available, it is unclear which have been validated and which would be most suitable for primary care practices. This systematic review aims to identify the most suitable falls risk assessment tool for the primary care setting (ie, requires limited time, no expensive equipment and no additional space) and that has good predictive performance in the assessment of falls risk among older people living independently.

Design A systematic review based on prospective studies. Methods An extensive search was conducted in the following databases: PubMed, Embase, CINAHL, Cochrane and PsycINF0. Tools were excluded if they required expensive and/or advanced software that is not usually available in primary care units and if they had not been validated in at least three different studies. Of 2492 articles published between January 2000 and July 2020 , 27 were included.

Results Six falls risk assessment tools were identified: Timed Up and Go (TUG) test, Gait Speed test, Berg Balance Scale, Performance Oriented Mobility Assessment, Functional Reach test and falls history. Most articles reported area under the curve (AUC) values ranging from 0.5 to 0.7 for these tools. Sensitivity and specificity varied substantially across studies (eg, TUG, sensitivity:10\%-83.3\%, specificity:28.4\%-96.6\%).

Conclusions Given that none of the falls risk assessment tools had sufficient predictive performance (AUC $<0.7$ ), other ways of assessing high falls risk among independently living older people in primary care should be investigated. For now, the most suitable way to assess falls risk in the primary care setting appears to involve asking patients about their falls history. Compared with the other five tools, the falls history requires the least amount of time, no expensive equipment, no training and no spatial adjustments. The clinical judgement of healthcare professionals continues to be most important, as it enables the identification of high falls risk even for patients with no falls history.

Trial registraion number The Netherlands Trial Register, NL7917; Pre-results.

\section{INTRODUCTION}

Worldwide, falls are the second leading cause of accidental or unintentional injury deaths. ${ }^{1}$ On average, one of every three people aged 65

\section{STRENGTHS AND LIMITATIONS OF THIS STUDY}

$\Rightarrow$ This review is built on extensive literature regarding falls risk assessment tools that are suitable for the primary care setting and representations of their predictive performance.

$\Rightarrow$ We endeavoured to reduce bias by only including falls risk assessment tools that have been validated at least three times in different studies and by assessing the risk of bias.

$\Rightarrow$ Given that different studies used different cut-off scores, addressed modified versions of the same tools and presented different outcome measures, it was difficult to combine the results and reach a convincing conclusion.

years or older falls at least once a year, ${ }^{2}$ and an estimated 646000 people die each year due to the consequences of falls. ${ }^{1}$ These numbers are increasing as society ages. ${ }^{3}$ The consequences of falls can range from scratches or bruises to hip fractures, brain injuries or even death. ${ }^{45}$ Falls can have a major, long-lasting negative impact on the quality of life and selfmanagement of older people. ${ }^{4-6}$ The treatment and rehabilitation of falls incidences are correlated with high costs in the healthcare sector. ${ }^{57}$ Therefore, the provision of falls prevention is important for older people.

Society is ageing, and older people are living independently at home for longer. ${ }^{3}$ The first point of contact for health problems is the general practitioner (GP). The approaches adopted by GPs vary, with some providing no falls prevention care at all, while others are quite active with regard to falls prevention. Given that only $20 \%$ of all older patients inform their GPs about their falls, GPs are unaware of the occurrence of $80 \%$ of the falls among their patients ${ }^{89}$ and they are thus likely not to know which of their patients are at risk of falls. This situation results in a delay or lack of treatment for falls risk among older people, despite the availability of potentially effective falls prevention interventions. ${ }^{10-14}$ 
The early identification of high falls risk among older people is a prerequisite to providing adequate care in time to reduce the risk of falls. Many tools are available for assessing falls risk, including the Timed Up and Go (TUG) test, the Tinetti Balance, the Berg Balance Scale (BBS) and the American Geriatrics Society/British Geriatrics Society guidelines for clinical practice. In a previous review, Gates et al summarise the accuracy of tools for predicting the risk of falling among older adults living in communities. They conclude that there is insufficient evidence to show that any instrument was adequate for predicting falls and they neither report nor consider implications for practice. It thus remains unclear which falls risk assessment tools have good predictive performance and might be suitable for practice.

The high workload associated with primary care places constraints on the time of practitioners. ${ }^{15} 16$ They also have limited resources for expensive equipment (eg, platforms, sensors), and their practices generally have little space ${ }^{17-20}$ A suitable falls risk assessment tool for primary care settings should therefore require limited time, no expensive equipment and no space adjustments. This systematic review aims to identify falls risk assessment tools that are the most suitable for primary care (ie, quick ( $<5 \mathrm{~min})$, no expensive equipment or specific resources required) and that have demonstrated good predictive performance in assessing the risk of falls among older people living independently. In this study, an assessment tool is understood as a tool that defines the nature of a specific problem: whether a patient does or does not have a high risk of falls. ${ }^{21}$ No additional assessment is required to identify high or low falls risk. Additional assessment is needed only to explore which intervention is needed to reduce a patient's risk of falls.

\section{METHODS}

\section{Study selection}

A systematic literature search was conducted in the following databases: PubMed, Embase, CINAHL, Cochrane and PsycINFO, using the search keywords presented in figure 1 (see online supplemental additional file 1). Medical Subject Headings (MeSH) terms were used when possible. Additional articles were included after snowballing. The flowchart for the literature search is displayed in figure 2.

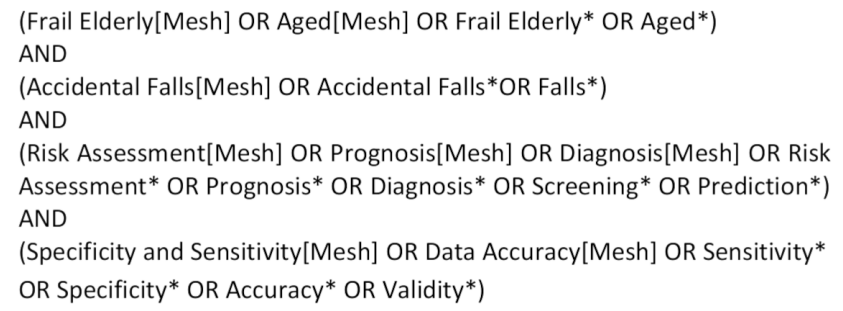

Figure 1 Search keywords.

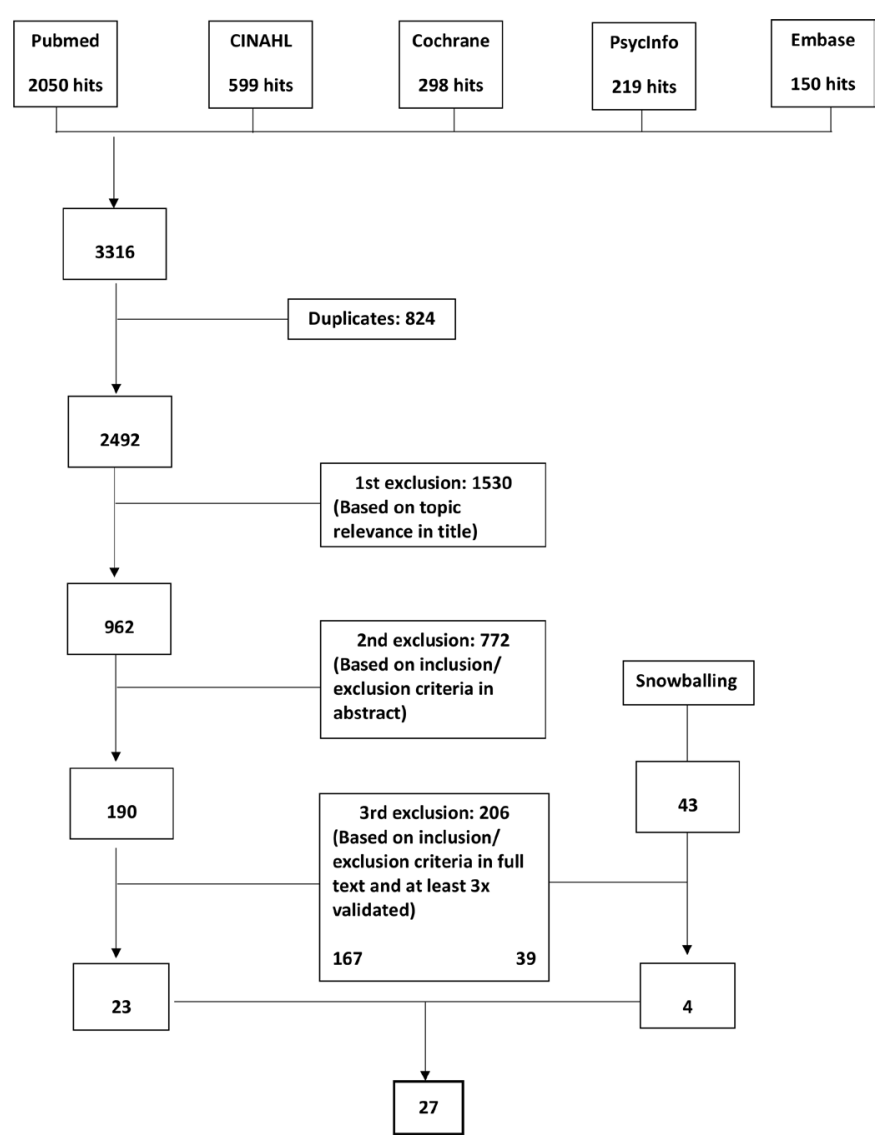

Figure 2 Flowchart for the literature search.

\section{Eligibility criteria and study selection}

The proportion of older people is increasing, and the current population of older people is ageing differently than was the case 20 years ago (eg, people are becoming older and are more vulnerable to chronic diseases)..$^{22} 23$ Given the importance of validating suitable falls risk assessment tools in the current population of older people, the review included articles published between January 2000 and July 2020 that met the criteria for inclusion (as presented in figure 3 ).

This review includes only prospective studies, thus making it possible to summarise the predictive performance of falls risk assessment tools. ${ }^{24}$ In addition, our final analysis includes only tools that have been assessed in at least three different studies. This was done in order to ensure the validity of the tools that were included, as studies are likely to differ (eg, in terms of the age, sex or frailty of the selected population).

The first round of exclusion based on title was performed by WMAM. All articles from the second round of exclusion based on abstract were reviewed by WMAM. In addition, JCK, CJL and IAMvdG each reviewed 67 articles from a sample of 200 articles from the second round of exclusion. Given the high level of agreement between the reviewers, only the sample of 200 articles was reviewed independently by two reviewers to identify differences in scoring. For the third round of exclusion, WMAM reviewed all full texts, with JCK, CJL and IAMvdG each 
Articles were included when they met the following inclusion criteria:

1. Prospective studies in which the primary or secondary purpose was to evaluate the performance of one or more fall risk assessment tools for predicting fallers.

2. The participants were older people living in the community or substantially independently

3. Full articles published in English, Dutch or German

Articles were excluded when they met one or more of the following exclusion criteria:

1. Fall risk assessment tools which require expensive computer software programs, other advanced expensive software or instruments not available in usual primary care units (e.g. sensors, electronical platforms, force plates).

2. Literature reviews and studies with no follow up of fall incidents.

3. No reported Area Under the Curve (AUC), sensitivity or specificity of the fall risk assessment tools.

4. Assessment tools specifically developed for or only tested on populations with a specific disease (e.g. cancer, diabetes, Parkinson etc.)

5. The participants were living in hospital or other institutionalised settings

Figure 3 Eligibility criteria.

reviewing one-third of all full texts. Differences between reviewers were discussed until consensus was reached. In total, 26 articles were included in this study.

\section{Quality appraisal}

The quality of the included studies was assessed independently by two reviewers (WMAM, together with JCK, CJL or IAMvdG) using the Quality in Prognosis Studies tool. $^{25} 26$ Articles were classified as being of low quality $(*)$, referring to high potential bias; moderate quality (**), referring to moderate potential bias; or high quality $(* * *)$, referring to low potential bias. The reviewers resolved differences through discussion until consensus was reached.

\section{Analysis}

This review investigates the predictive performance of prognostic tests for predicting the likelihood of experiencing a fall. The predictive performance of a prognostic test is often described similarly to that of diagnostic tests, based on diagnostic accuracy. ${ }^{24}$ In this review, diagnostic accuracy refers to the ability to discriminate accurately between fallers and non-fallers according to various measures, including sensitivity, specificity and area under the curve (AUC). ${ }^{27}$ To this end, data regarding sensitivity, specificity and AUC were extracted from the articles and described.

Sensitivity refers to the ability to classify individuals correctly as being at risk of falls, and specificity refers to the ability to classify individuals correctly as not being at risk of falls. ${ }^{28}$ A diagnostic test has good predictive value if sensitivity and specificity are $>70 \% .^{29}$ The AUC is the area under the receiver operating characteristic (ROC) curve, which represents the accuracy of the test. The ROC curve can be used to select the best cut-off score for most optimal sensitivity and specificity, with greater AUC reflecting a better test. The accuracy of a diagnostic test is considered good or excellent if the AUC is $>0.7 .{ }^{27}$
We ranked the outcomes, taking into account the cut-off values for good sensitivity, specificity and AUC. ${ }^{27} 29$

When analysing the results, we also considered criteria regarding the suitability of falls risks assessment tools for the primary care setting. The time available to primary healthcare providers is limited, due to their high workload. ${ }^{15161920}$ They also have limited resources for expensive equipment (eg, platforms, sensors), and their practices generally have little space. ${ }^{17} 18$ When analysing the results, we therefore considered the following criteria for a suitable tool: limited time, no expensive equipment and no spatial adjustments.

\section{Patient and public involvement}

Before conducting the systematic review, an informal focus group was conducted with primary care professionals (four GPs, two practice nurses and three district nurses) - the end-users-to identify their needs and wishes regarding falls risk assessment tools. We used the results of this informal focus group, together with previous literature, to define the suitability criteria used in this study. This ensured that the perspective of primary care professionals was taken into account when analysing the results of the review. No patients were directly involved in this systematic review.

\section{RESULTS}

The 27 articles included in this review identify a total of six falls risk assessment tools. Each of these tools is described below and presented in table 1. Further details about the included articles are provided in online supplemental additional file 2 .

\section{Timed Up and Go test}

The TUG test takes only a few minutes to complete, and it was described in 14 studies. ${ }^{30-43}$ In this test, participants are asked to stand up from a chair, walk $3 \mathrm{~m}$, turn, walk 
ำ

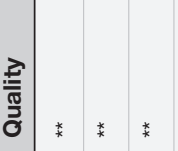

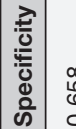

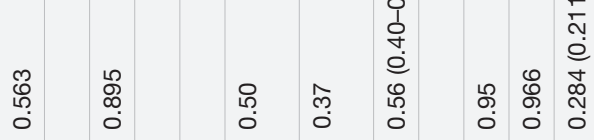

ช ชิ สิ ส
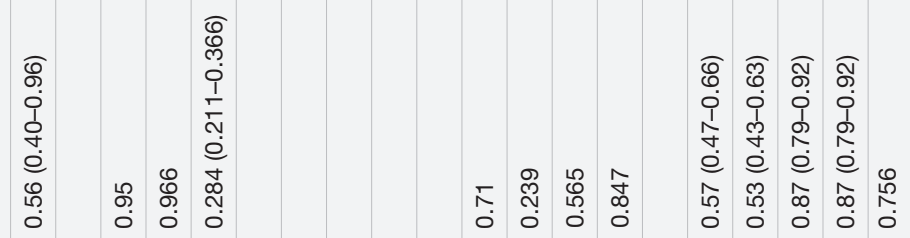

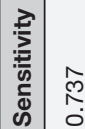

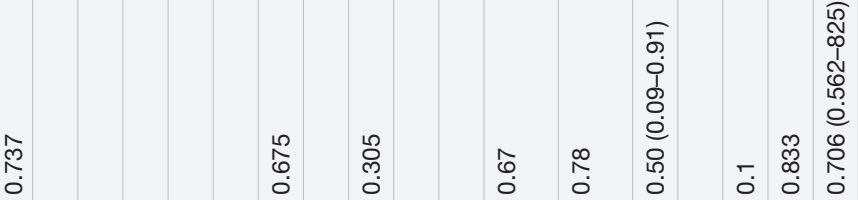

শิ 증 $\begin{array}{llll}0 & \\ 0 & 0 & 0 & 0 \\ 0 & 0 & 0 \\ 0 & 0 & 0 & 0 \\ 0 & 0 & 0 & 0 \\ 0 & 0 & 0 & 0\end{array}$

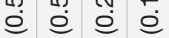

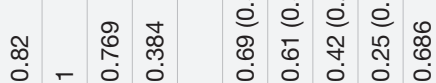

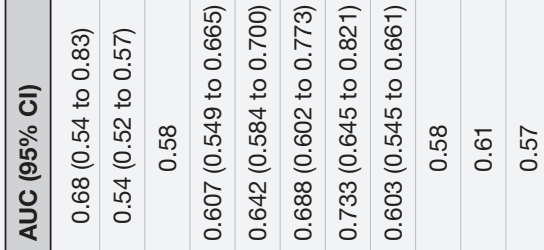

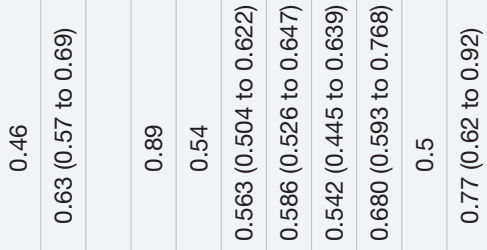

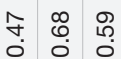

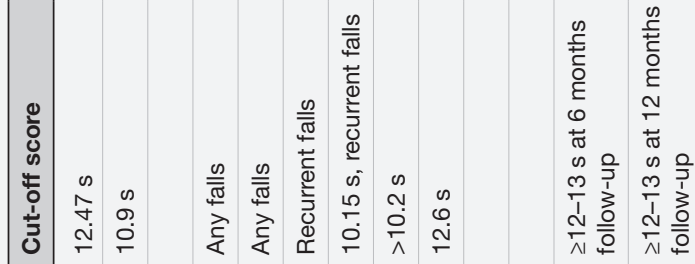
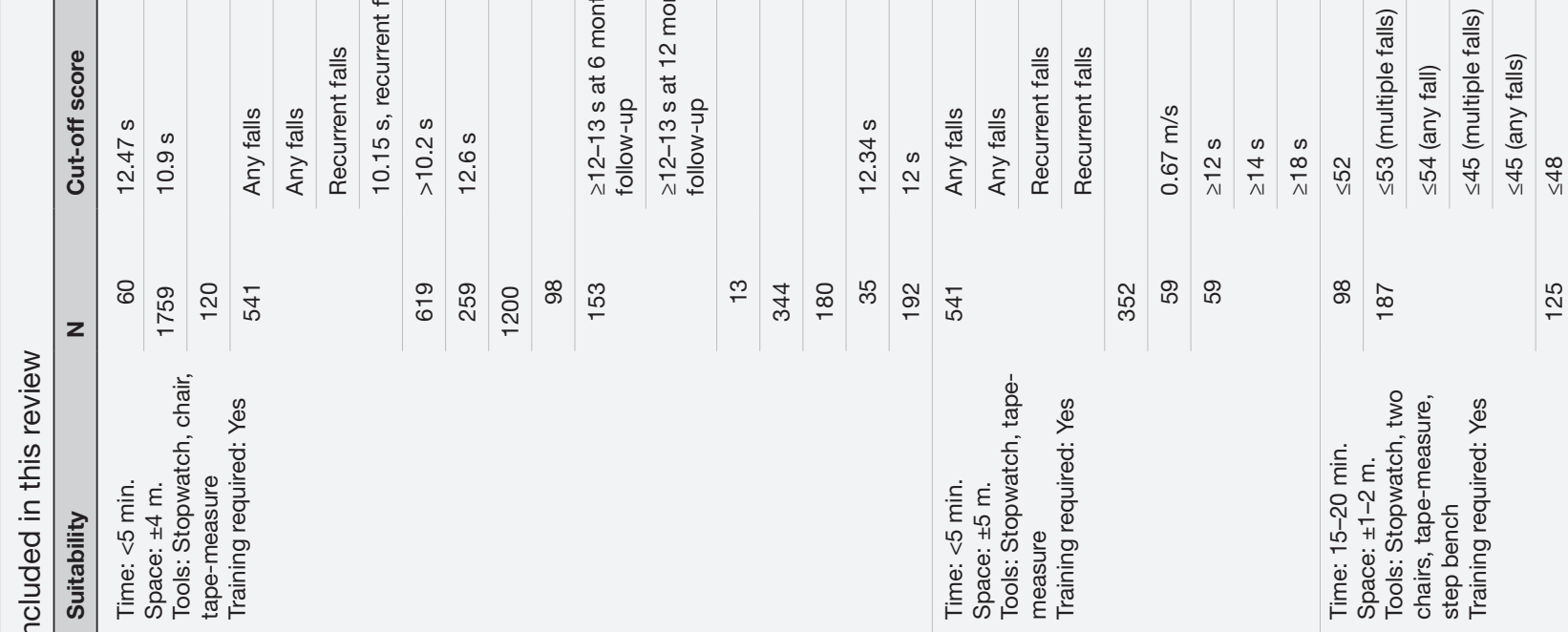

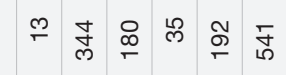

్ํㅇ คำ

$\stackrel{\infty}{\circ}$

$\stackrel{?}{\sim}$
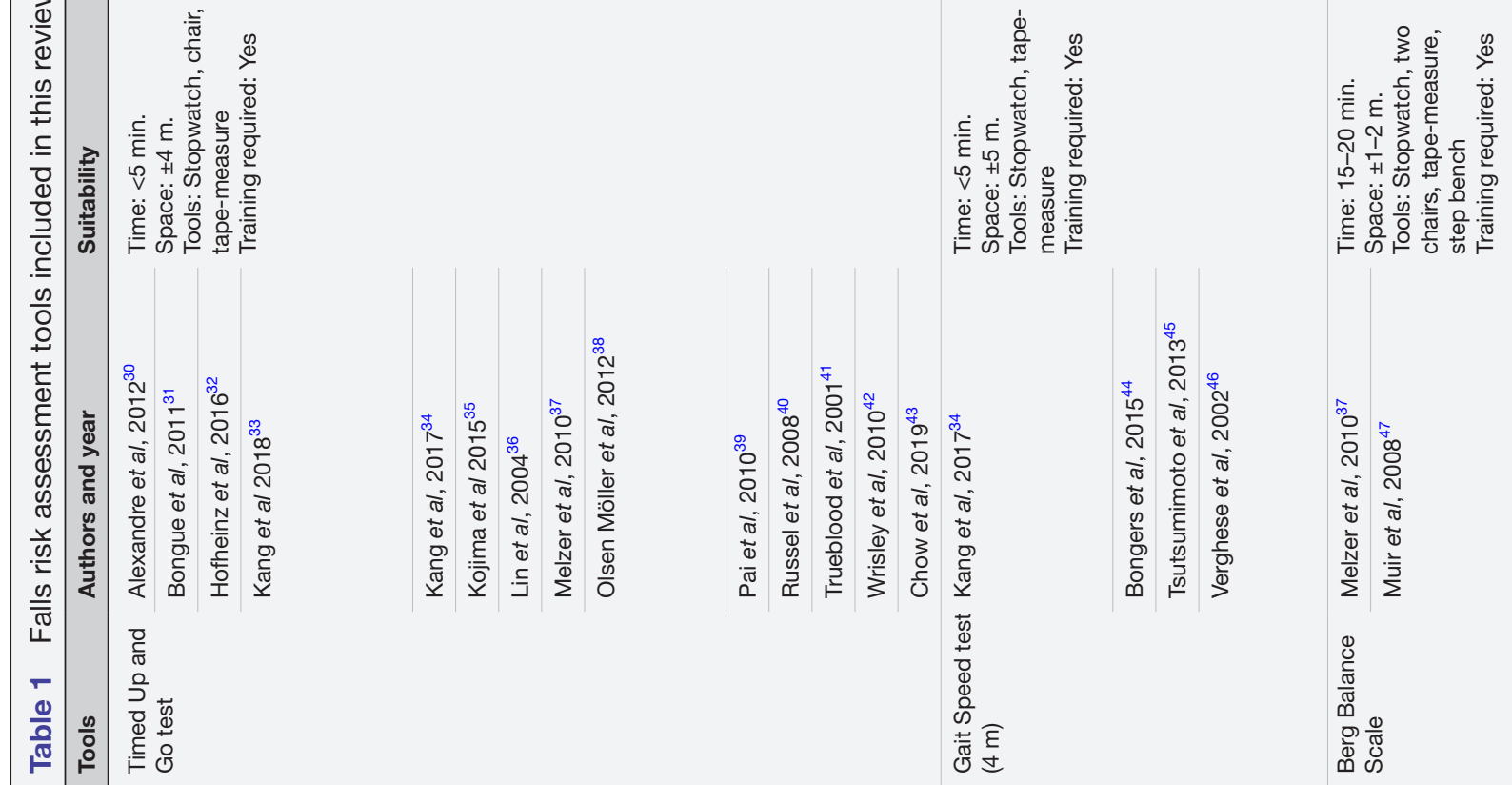

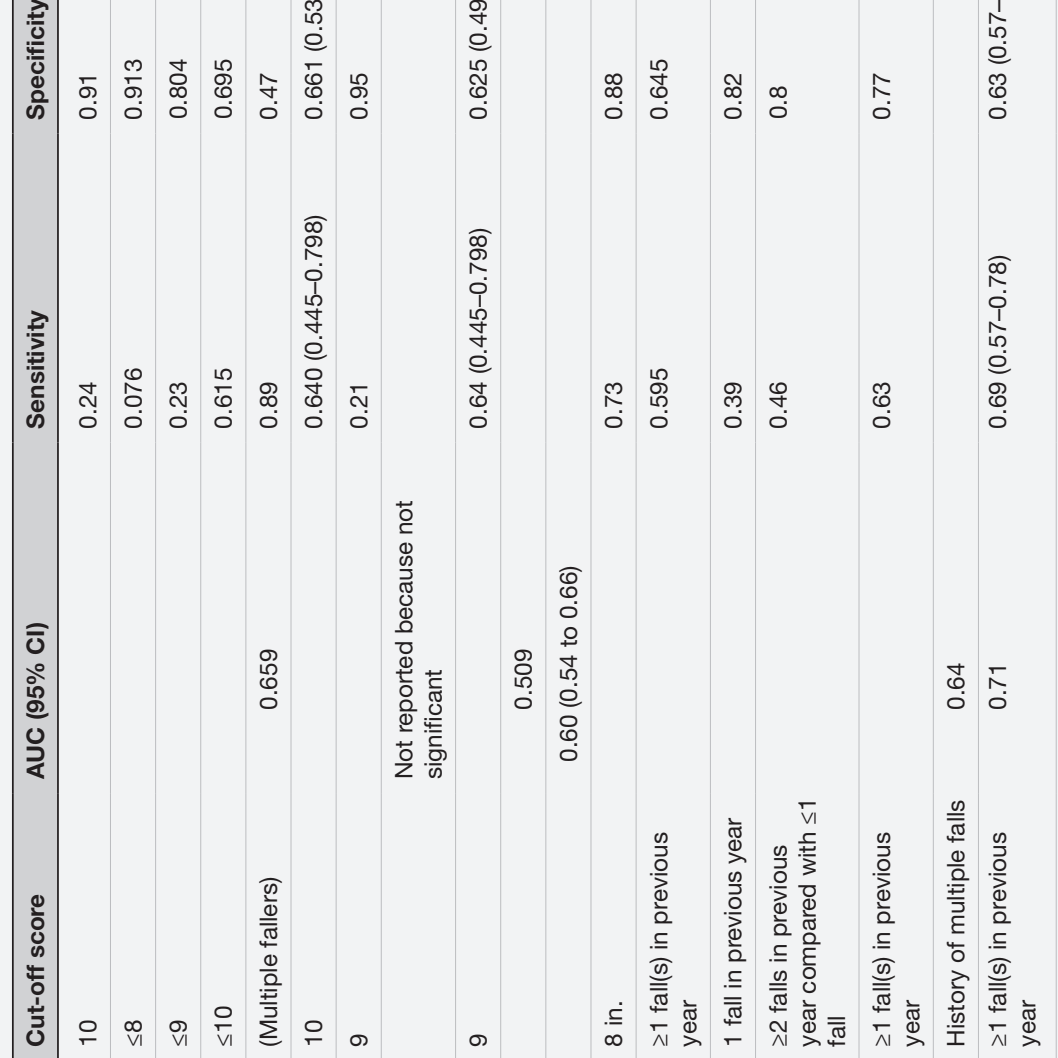

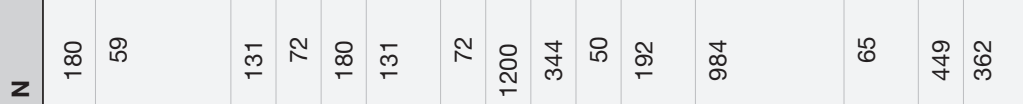

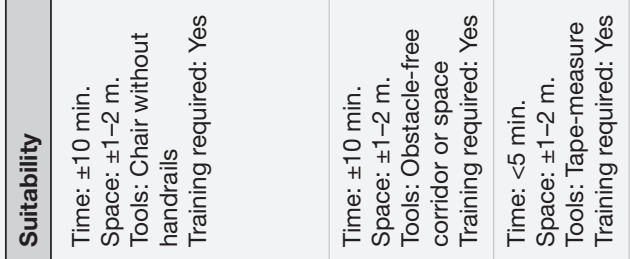


$3 \mathrm{~m}$ back and sit down again. The time taken to perform this task indicates high or low falls risk. The cut-off scores reported in the articles varied from $10.9 \mathrm{~s}$ to $13 \mathrm{~s}$. The AUC is described in 11 studies, ranging from 0.46 to 0.89 . In eight studies, sensitivity ranges from $10 \%$ to $83.3 \%$, and specificity ranges from $28.4 \%$ to $96.6 \%$.

\section{Gait Speed test}

The Gait Speed test, based on a distance of $4 \mathrm{~m}$, takes only a few minutes to complete, and it is evaluated in four studies. ${ }^{34-46}$ In this test, participants are asked to walk 4 $\mathrm{m}$ at their usual pace. The time taken to complete the task is recorded, and Gait Speed is calculated $(\mathrm{m} / \mathrm{s})$. An AUC value of 0.5 is reported by Bongers $e t a l^{44}$ and a value of 0.77 is reported by Tsutsumimoto $e t a l^{45}$ In an investigation of AUC for different follow-up periods and for any or recurrent falls, Kang $e t a l^{34}$ report values ranging from 0.54 to 0.68 . Sensitivity and specificity were reported in two studies, ${ }^{45}{ }^{46}$ ranging from $38.4 \%$ to $100 \%$ and from $23.9 \%$ to $84.7 \%$, respectively, depending on the cut-off scores.

\section{Berg Balance Scale}

The BBS evaluates a participant's balance based on 14 items scored along a 5-point Likert scale and takes 15-20 min to complete. The score for each item ranges from 0 to 4 points, with an overall maximum score of 56 points. Balance is evaluated by asking participants to perform a variety of sitting, transferring and standing positions. In an assessment of which cut-off scores on the BBS best predict the risk of falling, Muir $e t a l^{47}$ distinguish between single and multiple falls. They report an AUC of 0.68 for multiple falls with a cut-off score $\leq 53$, and an AUC of 0.59 for a single fall with a cut-off score $\leq 54$. A lower value of 0.47 is reported by Melzer et $a l .{ }^{37}$ Sensitivity and specificity are reported in studies by Muir et $a l^{47}(25 \%-69 \%)$ and by Ersoy et $a t^{48}(53 \%-87 \%)$.

\section{The Tinetti tests}

The Tinetti tests are widely used tests for assessing the risk of falling, but there are many variations. One is the Performance Oriented Mobility Assessment (POMA) total, which consists of two components to assess balance (POMA-B) and gait (POMA-G) and takes about $20 \mathrm{~min}$ to complete. For the POMA-B test, which is assessed in four studies, ${ }^{41464950}$ participants are asked to perform nine different movements to assess balance. Depending on the cut-off scores, sensitivity ranges from $23 \%$ to $89 \%$, with specificity ranging from $47 \%$ to $91.3 \%$. An AUC of 0.66 is reported by Bizovska et $a{ }^{49}$ but no cut-off scores are specified, and the comparison concerns multiple falls, thus excluding single falls. In the POMA-G, participants are asked to perform six different movements to assess gait. It is recommended to conduct this test in a corridor. The only study to specify the space used for the test is by Bizovska $e t a l^{49}$ : a well-lit corridor with a length of 30 m. Faber et $a l^{\tilde{D}^{0}}$ and Trueblood $e t a l^{41}$ report sensitivities ranging from $21 \%$ to $64 \%$ and specificities ranging from
$63 \%$ to $95 \%$. Bizovska et $a l^{49}$ do not report any specific results, as they found no significant differences between fallers and non-fallers in relation to the POMA-G.

\section{The Functional Reach test}

The Functional Reach (FR) test is validated in three studies. ${ }^{3640}{ }^{51}$ In this test, participants are asked to hold their arms in front of them in an angle of 90 degrees, stretch forward as far as possible and return to the starting position. The distance between the starting position and the stretched position is used as an indicator of the risk of falling. This test takes less than 5 min to complete. The AUC is reported in two studies, ${ }^{36}{ }^{40}$ varying from 0.51 to 0.60 . Murphy et $a \Gamma^{51}$ mention a sensitivity of $73 \%$ and a specificity of $88 \%$.

\section{Falls history}

Five studies explore the accuracy of falls history (FH) ${ }^{52-56}$ which takes only a few minutes to assess. These five studies apply different definitions of $\mathrm{FH}$, with the most common being at least one fall in the previous year. Tiedemann $e t$ $a b^{56}$ and Nitz et $a b^{55}$ report AUC values ranging from 0.64 to 0.71 . Sensitivity and specificity are explored in four studies, with sensitivity ranging from $39 \%$ to $69 \%$ and specificity ranging from $63 \%$ to $82 \%$.

\section{Quality appraisal}

The methodological quality of all articles was assessed (see table 1). Three articles were classified as high quality, 21 articles as moderate quality and 3 articles as low quality.

\section{DISCUSSION}

This study aimed to identify falls risk assessment tools that are suitable for the primary care setting (ie, they require limited time, no expensive equipment and no additional space) and that have good predictive performance in assessing the risk of falling among older people who are living independently. This systematic review identifies six falls risk assessment tools for the primary care setting. The vast majority of the included studies identify the falls risk among older people over a period of 12 months (mean: 15 months; minimum: 6 months; maximum: 9 years; see online supplemental additional file 2). None of these tools appears to be adequate in discriminating between people who are and are not at high risk of falling, taking into account the thresholds for good diagnostic accuracy (AUC $>0.7)$, as proposed by Šimundić. ${ }^{27}$ These findings do not change when considering only the articles of moderate and high quality. Four studies report AUC values $>0.7$ for the TUG test, ${ }^{33}{ }^{42}$ Gait Speed test ${ }^{45}$ and $\mathrm{FH}^{56}{ }^{56}$ thereby indicating good diagnostic accuracy. ${ }^{27}$ In most of the articles, however, the AUC values range from 0.5 to 0.7 , thus indicating insufficient diagnostic accuracy for all of the tools addressed. Furthermore, the sensitivity and specificity of the same tool varied substantially across studies. We are therefore unable to draw convincing conclusions.

The results of this review are corroborated by other studies. For example, even though the TUG test is widely used to assess 
falls risk, other studies have also reported a lack of predictive ability for this test with regard to falls. ${ }^{57}{ }^{58}$ Furthermore, as stated by Gates $e t a l,{ }^{59}$ 'At present, recommending any screening test for routine clinical use is not possible. Despite the number of studies that have been conducted, no strong evidence exists that any screening test is useful for identifying fallers' (Gates et al, p1113-1114). ${ }^{59}$ The current systematic review, conducted 13 years later, leads to the same conclusion. The lack of conclusive evidence to identify falls risk assessment tools with adequate predictive performance and accuracy persists to date. It is therefore impossible to select an assessment tool based on predictive performance. Our review nevertheless adds valuable information to the existing body of literature concerning the tool that is currently most suitable for use by primary care providers to identify patients who are at high risk of falls.

Primary healthcare providers have limited time and lack resources for expensive equipment, space and training. ${ }^{15-20}$ In light of these constraints, the results of this study suggest that the most suitable tool is $\mathrm{FH}$, as it takes only a few minutes to conduct and requires no training, expensive equipment or spatial adjustments. The BBS and the Tinetti tests would not be suitable, as they take 15-20 min to complete and require training to conduct. The TUG and Gait Speed tests are both quick ( $<5 \mathrm{~min})$, but they require training and space $(>4 \mathrm{~m})$ to conduct. Although the FR test is quick $(<5 \mathrm{~min})$ and does not require much space, it requires more training than $\mathrm{FH}$ and the AUC values reported are lower than those for FH.

Despite the fact that it is insufficient, the diagnostic accuracy of $\mathrm{FH}$ is the same or even better than that of most of the other five falls risk assessment tools (see table 1). Based on the clinometric evaluation of four falls risk assessment tools, Barker $e t a l^{60}$ also identify FH as a suitable assessment tool, stating that 'the predictive validity of all tools was found to be low, with no tool offering greater ability to identify residents who would fall than a simple screening question "has the resident fallen in the past 12 months?"' (Barker et al, p919). ${ }^{60}$ Patient FH is also used in many multifactorial assessment tools and algorithms, and it appears to be an important factor in the risk of falling (OR: not significant-14.02). ${ }^{485} 5561-68$ The use of FH nevertheless eliminates the possibility of identifying first-time fallers. Although this is clearly a major disadvantage, older people might be less willing to start and complete falls prevention interventions if they have not previously experienced a fall. They often do not consider themselves at high risk of falling. ${ }^{69} 70$ The experience of a previous fall might therefore enhance motivation to start and complete a falls prevention intervention. ${ }^{71}$

According to a study by Nordin $e t a l,{ }^{72}$ the assessment of falls risk through the combination of clinical judgement and FH among a population of frail older people was superior to performance-based measures. Meyer et $a l^{73}$ even assert that the use of falls risk assessment tools should be avoided, 'since it has no clinical consequences other than the waste of scarce nursing resources' (Meyer et al, p421) ${ }^{73}$ Due to increasing work pressure ${ }^{15-18}$ and lack of awareness, ${ }^{74}$ healthcare professionals might not assess a patient's risk of falling based solely on clinical judgement, as it is not part of any systematic assessment strategy. The systematic assessment of falls risk by combining $\mathrm{FH}$ and the expertise of healthcare professionals might therefore be an adequate strategy.

\section{Practice recommendations}

In daily practice, GPs can ask their older patients during consultation if they have had a fall during the past 12 months. Even if a patient has not had a fall, the GP might still identify a high falls risk based on clinical judgement (eg, walking or sitting difficulties due to strength and balance problems, dizziness, use of benzodiazepines, visual impairment). If a high falls risk is suspected after such a brief assessment, the GP could investigate the underlying cause of the falls risk by conducting a multifactorial assessment so that adequate care can be provided. It should be noted that, in this study, FH is defined as an assessment tool and not as a screening tool. A falls risk assessment tool defines the nature of the problem, and thus whether a patient is or is not at high risk of falling. ${ }^{21}$ No additional assessment is required to identify high or low falls risk. Additional assessment (eg, multifactorial assessment) is needed only to determine which intervention is needed in order to reduce a patient's high falls risk. Screening tools are intended to evaluate the possible presence of specific problems. A screening tool would require additional assessment in order to verify that a patient has a high falls risk. ${ }^{21}$

Depending on the organisation of the GP practice, the GP could also refer the patient to another healthcare provider (eg, a practice nurse specialised in geriatric care), who might have more time to investigate the underlying cause of the falls risk. A patient's falls risk could be reduced by conducting a brief falls risk assessment that leads to a comprehensive multifactorial assessment to identify the underlying causes, followed by multifactorial interventions that address any risk factors that have been identified. ${ }^{76-78}$ The clinical practice guidelines of the American Geriatrics Society/British Geriatrics Society recommend conducting falls risk assessments annually. ${ }^{79}$

\section{Strengths and limitations}

This review was not registered at PROSPERO, the international prospective register of systematic reviews. This could have caused duplication of review topics. Nonetheless, no ongoing reviews were found in the PROSPERO register that specifically focus on suitability of falls risk assessment tools for the primary care setting.

In this review, the initial screening of titles and abstracts was performed by one researcher (WMAM). For the second round of selection, a sample of 200 articles was reviewed independently by a second researcher (JCK, CJL or IAMvdG), based on abstract ( $>95 \%$ consensus). Even though this is an acceptable procedure according to the Cochrane Handbook for Systematic Reviews of Interventions, each screening step should ideally be performed by at least two people working independently. ${ }^{80}$ Our results 
might therefore be subject to bias due to our method of study selection.

The results of this review were difficult to combine. Different studies used different cut-off scores, addressed modified versions of the same tests and presented different outcome measures. These differences between studies made it difficult to arrive at a convincing conclusion based on the results.

Given that we have included at least three studies for each tool, it would seem feasible to conduct a metaanalysis for each tool. We did not do this, however, for two reasons. First, the diversity between studies assessing the same tools was quite high. For example, there were substantial differences in cut-off scores, follow-up periods and study populations (eg, in terms of sex, age), as well as in the criteria for inclusion and exclusion and the quality of the studies. These differences rendered a meta-analysis unsuitable for most tools. Second, the results of our study are clear without conducting a meta-analysis: none of the six tools identified in the review appears to be adequate in discriminating between people who are and are not at high risk of falling, taking into account the thresholds for good diagnostic accuracy (AUC $>0.7$ ), as proposed by Simundić. ${ }^{27}$ Another limitation is related to the possibility of publication bias against studies with worse outcomes, which might have led to an overestimation of the predictive performance of the falls risk assessment tools that were included. All of these limitations support our conclusion that none of the tools addressed has sufficient predictive performance.

\section{Further research}

The underlying cause of falls is often multifactorial and complex. This makes it difficult, if not impossible to adequately identify people who are at high risk of falling using only a physical test or brief questionnaire. None of the falls risk assessment tools identified in this review, all of which focus on falls history, balance, gait and/or strength problems, is capable of adequately identifying older people with high falls risk. It is therefore important to investigate other ways of assessing high falls risk in the primary care setting among older people who are living independently. The predictive performance of falls risk assessment tools could potentially be enhanced by developing a multifactorial assessment tool that also takes into account a person's behaviour and environment.

Taken together, the results of this systematic review indicate that the predictive performance of the six falls risk assessment tools identified in the studies reviewed is insufficient. Overall, FH appears to be the same or even better than the other five tools. In addition, this tool is most suitable for the primary care setting, as it is quick and does not require equipment, space or training. The combination of FH and the clinical judgement of a healthcare professional could be a promising strategy in the primary care setting for identifying older people who are at high risk of falling, such that they can be provided with adequate falls prevention care. This could reduce both falls and fear of falling, thereby maintaining or improving quality of life and prolonging autonomy for older people.

Contributors WMAM conducted the systematic review and wrote the manuscript. JCK, CJL and IAMvdG reviewed articles for inclusion, reviewed the quality check and provided feedback on the manuscript. All authors read and approved the final manuscript.

Funding This work was supported by ZonMw, the Netherlands Organisation for Health Research and Development (Grant Number 531001210).

Competing interests None declared.

Patient consent for publication Not required.

Provenance and peer review Not commissioned; externally peer reviewed.

Data availability statement Data are available upon reasonable request. All data relevant to the study are included in the article or uploaded as supplemental information. All data relevant to the study are included in the article or uploaded as supplementary information. Additional data are available upon reasonable request from the first author.

Supplemental material This content has been supplied by the author(s). It has not been vetted by BMJ Publishing Group Limited (BMJ) and may not have been peer-reviewed. Any opinions or recommendations discussed are solely those of the author(s) and are not endorsed by BMJ. BMJ disclaims all liability and responsibility arising from any reliance placed on the content. Where the content includes any translated material, BMJ does not warrant the accuracy and reliability of the translations (including but not limited to local regulations, clinical guidelines, terminology, drug names and drug dosages), and is not responsible for any error and/or omissions arising from translation and adaptation or otherwise.

Open access This is an open access article distributed in accordance with the Creative Commons Attribution Non Commercial (CC BY-NC 4.0) license, which permits others to distribute, remix, adapt, build upon this work non-commercially, and license their derivative works on different terms, provided the original work is properly cited, appropriate credit is given, any changes made indicated, and the use is non-commercial. See: http://creativecommons.org/licenses/by-nc/4.0/.

ORCID iD

Wytske MA Meekes http://orcid.org/0000-0002-7806-9871

\section{REFERENCES}

1 World Health Organization. Falls, fact sheet, 2018. Available: https:// www.who.int/news-room/fact-sheets/detail/falls

2 Paul S. Falls: prevention and management. Geriatric Medicine Springer; 2018: 109-19.

3 World Health Organization. Ageing and health, 2018. Available: https://www.who.int/news-room/fact-sheets/detail/ageing-andhealth

4 Terroso M, Rosa N, Torres Marques A, et al. Physical consequences of falls in the elderly: a literature review from 1995 to 2010. European Review of Aging and Physical Activity 2014;11:51-9.

5 World Health Organization ALCU. WHO global report on falls prevention in older age; 2008.

6 El-Bendary N, Tan Q, C. Pivot F, et al. Fall detection and prevention for the elderly: a review of trends and challenges. International Journal on Smart Sensing Intelligent Systems 2013;6:1230-66.

7 Van der Does H, Baan A, Panneman M. Privé-ongevallen bij ouderen, Cijfers valongevallen in de privésfeer 2018.: VeiligheidNL; 2019.

8 Elders P. Vallen bij ouderen. Huisarts Wet 2009;52:683.

9 van der Werf G. De huisarts en Het vallen van patiënten in Het verzorgingshuis. Huisarts Wet 2005;48:50-3.

10 Faber MJ, Bosscher RJ, Chin A Paw MJ, et al. Effects of exercise programs on falls and mobility in frail and Pre-Frail older adults: a multicenter randomized controlled trial. Arch Phys Med Rehabil 2006;87:885-96.

11 Zijlstra GAR, van Haastregt JCM, Kempen GIJM. 'Zicht op Evenwicht': een effectieve interventie om bezorgdheid om te vallen en gerelateerd vermijdingsgedrag bij ouderen te verminderen. Tijdschr Gerontol Geriatr 2012;43:164-74.

12 Weerdesteyn V, Rijken H, Geurts ACH, et al. A Five-Week exercise program can reduce falls and improve obstacle avoidance in the elderly. Gerontology 2006;52:131-41. 
13 Robertson MC, Devlin N, Gardner MM. Effectiveness and economic evaluation of a nurse delivered home exercise programme to prevent falls. 1: randomised controlled trial. BMJ 2001;322:697-701.

14 Campbell A, Robertson MC, Gardner MM. Falls prevention over 2 years: a randomized controlled trial in women 80 years and older. Age Ageing 1999;28:513-8.

15 Boekee S, Hoekstra H. Meer tijd voor de patiënt Newcom Research \& Consultancy B.V; 2018.

16 Blackburn M, Stathi A, Keogh E, et al. Raising the topic of weight in general practice: perspectives of GPs and primary care nurses. BMJ Open 2015;5:e008546.

17 McNeely J, Kumar PC, Rieckmann T, et al. Barriers and facilitators affecting the implementation of substance use screening in primary care clinics: a qualitative study of patients, providers, and staff. Addict Sci Clin Pract 2018:13:8

18 Rosário F, Santos MI, Angus K, et al. Factors influencing the implementation of screening and brief interventions for alcohol use in primary care practices: a systematic review using the COM-B system and theoretical domains framework. Implementation Science 2021;16:1-25.

19 Westert GP, Jabaaij L, Schellevis FG. Morbidity, performance and quality in primary care: Dutch general practice on stage. Radcliffe Publishing, 2006.

20 Pérez-Francisco DH, Duarte-Clíments G, del Rosario-Melián JM, et al, eds. Influence of workload on primary care nurses' health and burnout, patients' safety, and quality of care: Integrative Review. Healthcare. Multidisciplinary Digital Publishing Institute, 2020.

21 Center for Substance Abuse Treatment. Substance abuse treatment: addressing the specific needs of women; 2009.

22 United Nations. World population ageing 2017-Highlights. New York Department of Economic and Social Affairs, United Nations; 2017.

23 van Oostrom SH, Gijsen R, Stirbu I, et al. Time trends in prevalence of chronic diseases and multimorbidity not only due to aging: data from general practices and health surveys. PLoS One 2016;11:e0160264.

24 Rector TS, Taylor BC, Wilt TJ. Chapter 12: systematic review of prognostic tests. J Gen Intern Med 2012;27:94-101.

25 Hayden JA, van der Windt DA, Cartwright JL, et al. Assessing bias in studies of prognostic factors. Ann Intern Med 2013;158:280-6.

26 Riley RD, Moons KGM, Snell KIE, et al. A guide to systematic review and meta-analysis of prognostic factor studies. BMJ 2019;6:k4597.

27 Šimundić A-M. Measures of diagnostic accuracy: basic definitions. EJIFCC 2009;19:203.

28 Parikh R, Mathai A, Parikh S, et al. Understanding and using sensitivity, specificity and predictive values. Indian J Ophthalmol 2008;56:45

29 NICE CfCPa. Falls: assessment and prevention of falls in older people; 2013

30 Alexandre TS, Meira DM, Rico NC, et al. Accuracy of timed up and go test for screening risk of falls among community-dwelling elderly. Rev Bras Fisioter 2012;16:381-8.

31 Bongue $\mathrm{B}$, Dupré $\mathrm{C}$, Beauchet $\mathrm{O}$, et al. A screening tool with five risk factors was developed for fall-risk prediction in community-dwelling elderly. J Clin Epidemiol 2011;64:1152-60.

32 Hofheinz M, Mibs M. The prognostic validity of the timed up and go test with a dual task for predicting the risk of falls in the elderly. Gerontol Geriatr Med 2016;2:233372141663779.

33 Kang L, Chen X, Han P, et al. A screening tool using five risk factors was developed for Fall-Risk prediction in Chinese communitydwelling elderly individuals. Rejuvenation Res 2018;21:416-22.

34 Kang L, Han P, Wang J, et al. Timed up and go test can predict recurrent falls: a longitudinal study of the community-dwelling elderly in China. Clin Interv Aging 2017;12:2009-16.

35 Kojima G, Masud T, Kendrick D, et al. Does the timed up and go test predict future falls among British community-dwelling older people? prospective cohort study nested within a randomised controlled trial. BMC Geriatr 2015;15:38.

36 Lin $\mathrm{M}-\mathrm{R}$, Hwang $\mathrm{H}-\mathrm{F}$, Hu M-H, et al. Psychometric comparisons of the timed up and go, one-leg stand, functional reach, and Tinetti balance measures in community-dwelling older people. J Am Geriatr Soc 2004; $52: 1343-8$

37 Melzer I, Kurz I, Shahar D, et al. Do voluntary step reactions in dual task conditions have an added value over single task for fall prediction? A prospective study. Aging Clin Exp Res 2010;22:360-6.

38 Olsson Möller U, Kristensson J, Midlöv P, et al. Predictive validity and cut-off scores in four diagnostic tests for falls - a study in frail older people at home. Phys Occup Ther Geriatr 2012;30:189-201.

39 Pai Y-C, Wang E, Espy DD, et al. Adaptability to perturbation as a predictor of future falls: a preliminary prospective study. $J$ Geriatr Phys Ther 2010;33:50-5.
40 Russell MA, Hill KD, Blackberry I, et al. The reliability and predictive accuracy of the falls risk for older people in the community assessment (FROP-Com) tool. Age Ageing 2008;37:634-9.

41 Trueblood PR, Hodson-Chennault N, McCubbin A. Performance and Impairment-Based assessments among community Dwelling elderly: sensitivity and specificity. $J$ Geriatr Phys Ther 2001;24:2-6.

42 Wrisley DM, Kumar NA. Functional gait assessment: concurrent, discriminative, and predictive validity in community-dwelling older adults. Phys Ther 2010;90:761-73.

43 Chow RB, Lee A, Kane BG, et al. Effectiveness of the "Timed Up and Go" (TUG) and the Chair test as screening tools for geriatric fall risk assessment in the ED. Am J Emerg Med 2019;37:457-60.

44 Bongers KTJ, Schoon Y, Graauwmans MJ, et al. The predictive value of gait speed and maximum step length for falling in communitydwelling older persons. Age Ageing 2015;44:294-9.

45 Tsutsumimoto K, Doi T, Misu S, et al. Can the Ordered MultiStepping Over Hoop test be useful for predicting fallers among older people? A preliminary 1 year cohort study. Aging Clin Exp Res 2013;25:427-32.

46 Verghese J, Buschke $\mathrm{H}$, Viola L, et al. Validity of divided attention tasks in predicting falls in older individuals: a preliminary study. J Am Geriatr Soc 2002;50:1572-6.

47 Muir SW, Berg K, Chesworth B, et al. Use of the Berg balance scale for predicting multiple falls in community-dwelling elderly people: a prospective study. Phys Ther 2008;88:449-59.

48 Ersoy Y, MacWalter RS, Durmus B, et al. Predictive effects of different clinical balance measures and the fear of falling on falls in postmenopausal women aged 50 years and over. Gerontology 2009;55:660-5

49 Bizovska L, Svoboda Z, Janura M, et al. Local dynamic stability during gait for predicting falls in elderly people: a one-year prospective study. PLoS One 2018;13:e0197091.

50 Faber MJ, Bosscher RJ, van Wieringen PCW. Clinimetric properties of the performance-oriented mobility assessment. Phys Ther 2006;86:944-54

51 Murphy MA, Olson SL, Protas EJ, et al. Screening for falls in community-dwelling elderly. J Aging Phys Act 2003;11:66-80.

52 Coll-Planas L, Kron M, Sander S, et al. Accidental falls among community-dwelling older adults: improving the identification process of persons at risk by nursing staff. $Z$ Gerontol Geriatr 2006;39:277-82.

53 Gerdhem P, Ringsberg KAM, Åkesson K, et al. Clinical history and biologic age predicted falls better than objective functional tests. $J$ Clin Epidemiol 2005;58:226-32.

54 Lindemann U, Lundin-Olsson L, Hauer K, et al. Maximum step length as a potential screening tool for falls in non-disabled older adults living in the community. Aging Clin Exp Res 2008;20:394-9.

55 Nitz JC, Stock L, Khan A. Health-Related predictors of falls and fractures in women over 40. Osteoporos Int 2013;24:613-21.

56 Tiedemann A, Lord SR, Sherrington C. The development and validation of a brief Performance-based fall risk assessment tool for use in primary care. J Gerontol A Biol Sci Med Sci 2010;65:896-903.

57 Barry E, Galvin R, Keogh C, et al. Is the timed up and go test a useful predictor of risk of falls in community dwelling older adults: a systematic review and meta- analysis. BMC Geriatr 2014;14:14.

58 Schoene D, Wu SM-S, Mikolaizak AS, et al. Discriminative ability and predictive validity of the timed up and go test in identifying older people who fall: systematic review and meta-analysis. J Am Geriatr Soc 2013;61:202-8.

59 Gates S, Smith LA, Fisher JD, et al. Systematic review of accuracy of screening instruments for predicting fall risk among independently living older adults. JRRD 2008:45:1105-16.

60 Barker AL, Nitz JC, Low Choy NL, et al. Measuring fall risk and predicting who will fall: Clinimetric properties of four fall risk assessment tools for residential aged care. J Gerontol A Biol Sci Med Sci 2009;64A:916-24.

61 Bergland A, Jarnlo G-B, Laake K. Predictors of falls in the elderly by location. Aging Clin Exp Res 2003;15:43-50.

62 Buatois S, Perret-Guillaume C, Gueguen R, et al. A simple clinical scale to stratify risk of recurrent falls in community-dwelling adults aged 65 years and older. Phys Ther 2010;90:550-60.

63 Close JCT, Hooper R, Glucksman E. Predictors of falls in a high risk population: results from the prevention of falls in the elderly trial (PROFET). Emergency Medicine Journal 2003;20:421-5.

64 Mackenzie L, Byles J, D'Este C. Longitudinal study of the home falls and accidents screening tool in identifying older people at increased risk of falls. Australas J Ageing 2009;28:64-9.

65 Pluijm SMF, Smit JH, Tromp EAM, et al. A risk profile for identifying community-dwelling elderly with a high risk of recurrent falling: results of a 3-year prospective study. Osteoporos Int 2006;17:417-25. 
66 Sai AJ, Gallagher JC, Smith LM, et al. Fall predictors in the community dwelling elderly: a cross sectional and prospective cohort study. J Musculoskelet Neuronal Interact 2010;10:142-50.

67 Tromp AM, Pluijm SM, Smit JH, et al. Fall-risk screening test: a prospective study on predictors for falls in community-dwelling elderly. J Clin Epidemiol 2001;54:837-44.

68 Vermeulen J, Neyens JCL, Spreeuwenberg MD, et al. The relationship between balance measured with a modified bathroom scale and falls and disability in older adults: a 6-month follow-up study. J Med Internet Res 2015;17:e131.

69 Bunn F, Dickinson A, Barnett-Page E, et al. A systematic review of older people's perceptions of facilitators and barriers to participation in falls-prevention interventions. Ageing Soc 2008;28:449-72.

70 Loganathan A, Ng CJ, Tan MP, et al. Barriers faced by healthcare professionals when managing falls in older people in Kuala Lumpur, Malaysia: a qualitative study. BMJ Open 2015;5:e008460.

71 Kiami SR, Sky R, Goodgold S. Facilitators and barriers to enrolling in falls prevention programming among community dwelling older adults. Arch Gerontol Geriatr 2019;82:106-13.

72 Nordin E, Lindelöf N, Rosendahl E, et al. Prognostic validity of the Timed Up-and-Go test, a modified Get-Up-and-Go test, staff's global judgement and fall history in evaluating fall risk in residential care facilities. Age Ageing 2008;37:442-8.
73 Meyer G, Köpke S, Haastert B, et al. Comparison of a fall risk assessment tool with nurses' judgement alone: a cluster-randomised controlled trial. Age Ageing 2009;38:417-23.

74 Kinoshita M, Takeda H, Yamada C, et al. Characteristics of awareness and behavior of medical staff for prevention of falling accidents among inpatients. Fukushima J Med Sci 2019;65:13-23.

75 Chou WC, Tinetti ME, King MB, et al. Perceptions of physicians on the barriers and facilitators to integrating fall risk evaluation and management into practice. J Gen Intern Med 2006;21:117-22.

76 Hopewell S, Adedire O, Copsey BJ, et al. Multifactorial and multiple component interventions for preventing falls in older people living in the community. Cochrane Database Syst Rev 2018;7:CD012221.

77 Gillespie LD, Robertson MC, Gillespie WJ, et al. Interventions for preventing falls in older people living in the community. Cochrane Database Syst Rev 2012:CD007146.

78 Moyer VA. Prevention of falls in community-dwelling older adults: U.S. preventive services Task force recommendation statement. Ann Intern Med 2012;157:197-204.

79 Panel on Prevention of Falls in Older Persons, American Geriatrics Society and British Geriatrics Society. Summary of the updated American geriatrics Society/British geriatrics Society clinical practice guideline for prevention of falls in older persons. J Am Geriatr Soc 2011;59:148-57.

80 Higgins JP, Thomas J, Chandler J, et al. Cochrane Handbook for systematic reviews of interventions. John Wiley \& Sons, 2019. 